\title{
Usefulness of Vacuum-Assisted Closure Therapy in the Treatment of Esophageal Perforation Following Thyroidectomy
}

\author{
Anna Park ${ }^{1}$, Young Sam Yoo ${ }^{1}$, Jeong Hwan Choi ${ }^{1}$, and Eui Suk Chung ${ }^{2}$ \\ ${ }^{1}$ Departments of Otorhinolaryngology-Head and Neck Surgery, ${ }^{2}$ Thoracic and Cardiovascular Surgery, Sanggye Paik Hospital, \\ College of Medicine, Inje University, Seoul, Korea
}

\section{갑상선 절제술 후 발생한 식도천공 및 경부농양의 음압상처치료}

박안나 ${ }^{1} \cdot$ 유영삼 $^{1} \cdot$ 최정환 $^{1} \cdot$ 정의석 $^{2}$

인제대학교 의과대학 상계백병원 이비인후과학교실, ${ }^{1}$ 훙부외과학교실 ${ }^{2}$

\author{
Received October 7, 2016 \\ Revised December 19, 2016 \\ Accepted December 26, 2016 \\ Address for correspondence \\ Young Sam Yoo, MD \\ Department of Otorhinolaryngology- \\ Head and Neck Surgery, \\ Sanggye Paik Hospital, \\ College of Medicine, Inje University, \\ 1342 Dongil-ro, Nowon-gu, \\ Seoul 01757, Korea \\ Tel $+82-2-950-1104$ \\ Fax $+82-2-935-6220$ \\ E-mail entyoo@empal.com
}

Perforation of the cervical esophagus after thyroidectomy is a rare complication. Esophageal perforation is usually treated conservatively with simple surgical drainage and intravenous antibiotic therapy. If complicated by abscess, it needs aggressive surgery including resection and anastomosis. But the aggressive treatments mentioned have low success and high morbidity. Herein, we report a patient with complicated deep neck infection caused by esophageal perforation following thyroidectomy, which was successfully treated with multiple vacuumassisted closure and intravenous antibiotic therapy after the failure of simple suture and simple drainage as conservative managements.

Korean J Otorhinolaryngol-Head Neck Surg 2017;60(5):252-6

Key Words Cervical esophageal perforation · Deep neck infection · Thyroidectomy · Vacuum-assisted closure therapy.

\section{Introduction}

An esophageal perforation after thyroidectomy is a very rare complication, which may occur after surgery if the tumor tenaciously adheres to surrounding organs. ${ }^{1-5)}$

Most esophageal perforations in the neck can be treated with broad-spectrum antibiotics after simple suture. However, if a neck abscess occurs due to infection, complications including septic shock (16.8\%), pneumonia (10.8\%) and mediastinitis (1.98\%). Tracheostomy was necessary in $16.8 \%$ of patients. The mortality rate was $1.98 \%{ }^{6}{ }^{6}$

Despite the use of appropriate antibiotics and surgical drain-

This is an Open Access article distributed under the terms of the Creative Commons Attribution Non-Commercial License (http://creativecommons.org/licenses/by-nc/4.0) which permits unrestricted non-commercial use, distribution, and reproduction in any medium, provided the original work is properly cited. age, the perforation site may not improve and become worse, requiring a number of surgeries.

We report a case of intractable cervical esophageal perforation with deep neck infection that occurred after total thyroidectomy, which was successfully treated with vacuum-assisted closure (VAC) therapy application for a number of times after the failure of simple suture and simple drainage as conservative managements.

\section{Case}

A 61-year-old female visited our clinic complaining of hoarseness that had occurred 1 month ago. She had hypertension as an underlying disease, and laryngoscopic examination showed left vocal cord paralysis. Computed tomography (CT) revealed 
a $2 \times 2 \mathrm{~cm}$ low density with enhanced tumor in the left thyroid and internal low attenuated lymph node in the left supraclavicular area. Tumor mass was contact with surrounding trachea and esophagus (Fig. 1). Fine-needle aspiration cytology revealed a consistent with papillary carcinoma of undetermined significance. Under the diagnosis of thyroid papillary carcinoma and neck metastasis, total thyroidectomy and left anterior compartment selective neck dissection were performed. During operation, the enlarged, firm left thyroid lobe was densely adherent to the surrounding structure including the trachea and esophageal mucosa. Unusually sharp dissection was needed to remove mass. There were no definite defects in the surroundings immediate postoperatively. At the end of operation, suction drains were inserted and simple suture was done. The day after thyroidectomy, the patient's vital was stable and the color of drainage was clear. However, one day after oral feeding, patient complained of headache, back pain, respiratory discomfort, neck edema and tenderness with stable vital sign. The color of drainage became turbid and amount of it became double. Therefore the esopha-

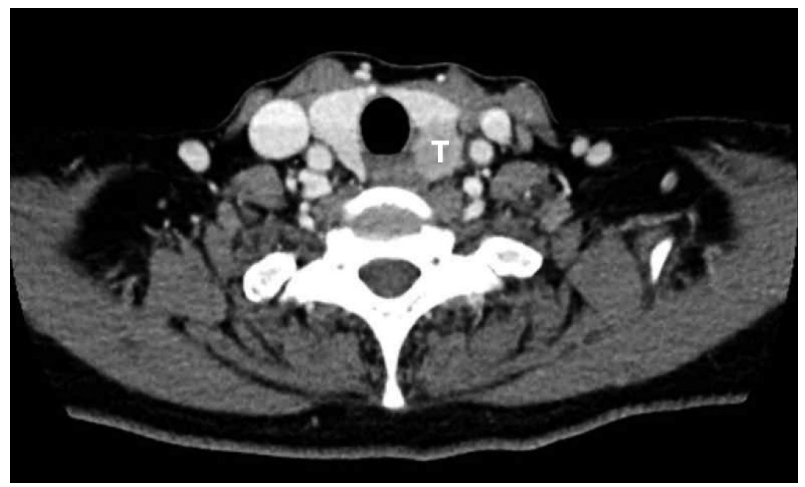

Fig. 1. Preoperative computed tomography of the neck shows low density tumor in the left thyroid lobe. The tumor mass is contact with esophagus and trachea. T: tumor.

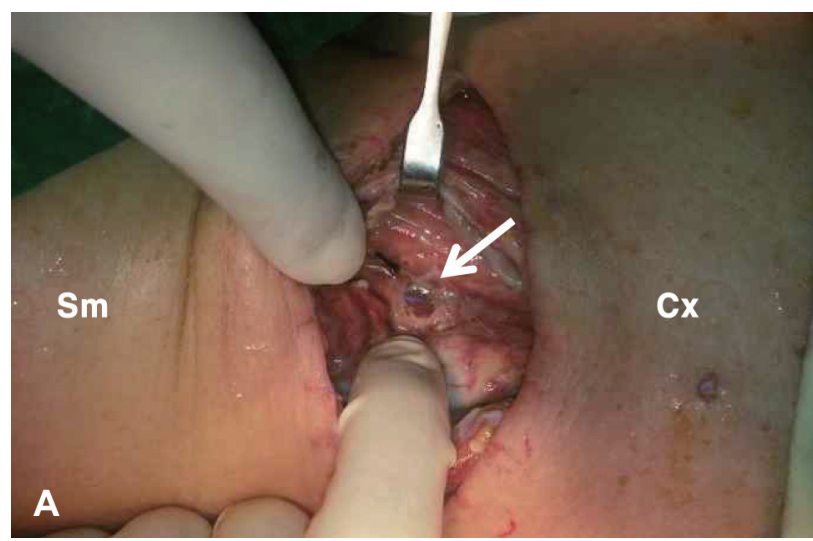

geal perforation was suspected. Immediate wound exploration showed dark brown material contaminating the whole surgical field. After copious irrigating the wound, a $5 \mathrm{~mm}$-sized perforation was found in upper cervical esophagus on left side (Fig. 2A).

After copious irrigation with normal saline, the perforation was repaired using 4-0 vicryl and the nasogastric tube was inserted (Fig. 2B). After operation, ceftriaxone and aminoglycoside used for 27 days until vancomycin replaced. One day after the first primary repair, the patient still complained of neck and chest swelling, despite the color of drainage comes clear. The body temperature of patient increased up to $39^{\circ} \mathrm{C}$, the white blood cell count and C-reactive protein (CRP) level were detected to $9850 / \mu \mathrm{L}$ and $27.9 \mathrm{mg} / \mathrm{dL}$. CT revealed fluid collection in the carotid space of both sides down to supraclavicular area, pleural effusion on the both lung, and enhanced lesion in upper mediastinum. Therefore, we decided to change

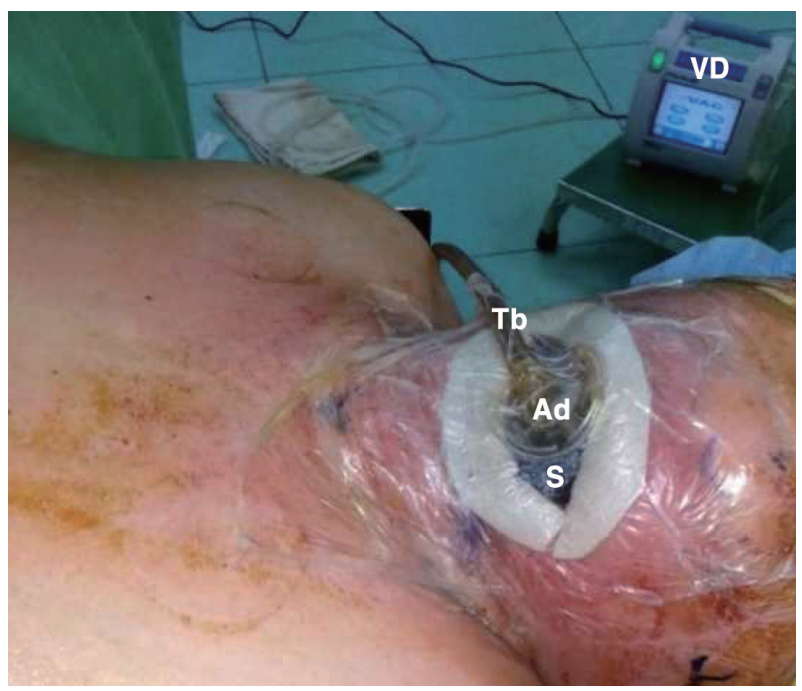

Fig. 3. Vacuum-assisted closure therapy set-up. S: sponge, Ad: adaptor, Tb: tube, VD: vacuum device.

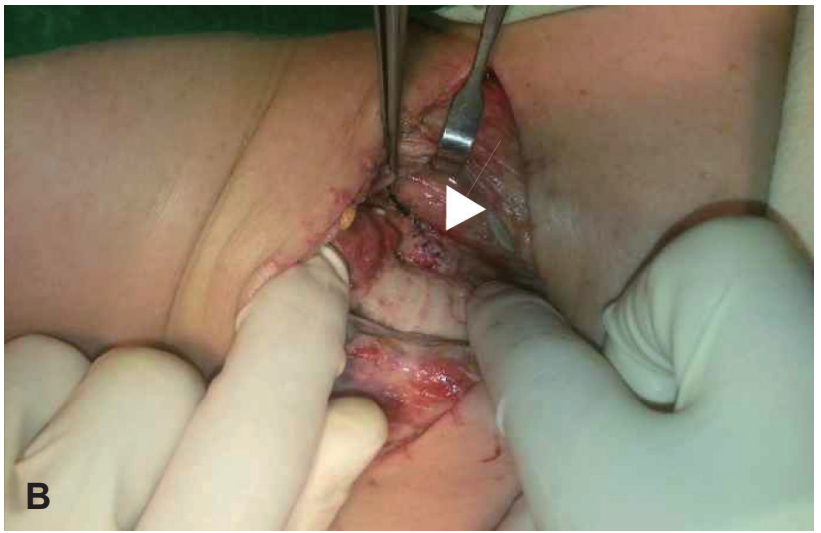

Fig. 2. Intraoperative photographs show (A) perforation of cervical esophagus on left side (arrow) and (B) repaired esophagus defect (arrowhead). Sm: submandible, Cx: chest. 


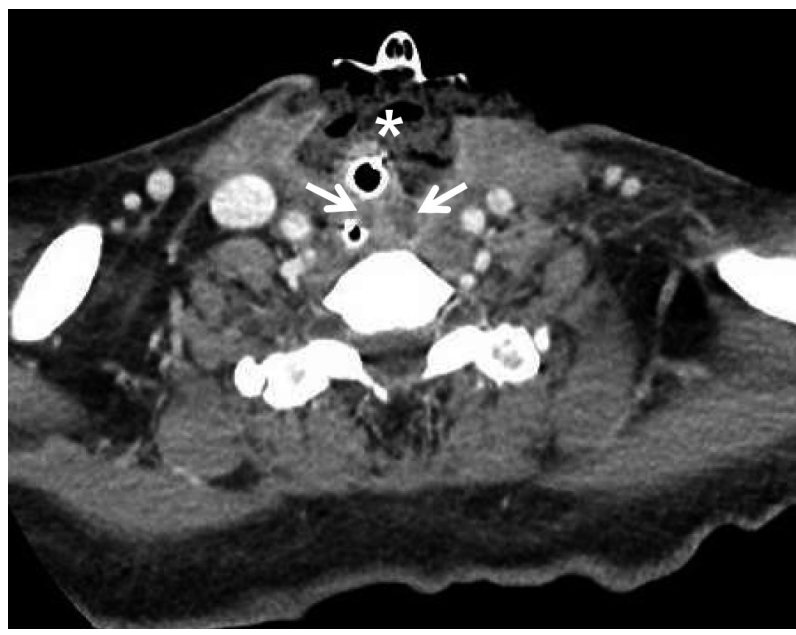

Fig. 4. Computed tomography on the day before the fifth drainage operation including VAC sponge change. Axial view shows fluid collection in middle neck close to anterior esophageal wall and left parapharyngeal space (arrows). Sponge inserted into anterior neck space (asterisks). VAC: vacuum-assisted closure.

the treatment of simple irrigation and drainage to VAC therapy (Figs. 3 and 4).

VAC therapy included cleaning the wound with irrigation, filling the open wound with surgical sponges, sealing the wound air-tightly using adhesive film and connection of the suction tube from the wound to a vacuum device (Curavac; Daewoong Medical, Seoul, Korea) with the suction pressure maintained at $125 \mathrm{~mm} \mathrm{Hg}$.

Five days after the first drainage operation, the 3rd drainage operation including VAC sponge change was performed. Perfusion irrigation and sponge replacement of the neck were performed 15 times every $3-5$ days until the wound showed improvement. From the day of esophageal perforation diagnosis, the patient consumed a liquid diet for 17 days to protect the wound from the reflux. Afterward it was replaced with a gastrostomy on the sixth drainage operation including VAC sponge change at patient's request.

Nineteen days after the first drainage operation, white blood cell count was $12520 / \mu \mathrm{L}$ and CRP level was $4.7 \mathrm{mg} / \mathrm{dL}$. In addition, platelet count and coagulation function gradually normalized.

Twenty-seven days after the first drainage operation, mild tracheal thinning and inflammation were observed next a esophageal perforation site on the 9th drainage operation including VAC sponge change. But it improved after repeated irrigation and sponge replacement.

Streptococcus parasanguinis, Streptococcus mitis, Enterococcus faecalis, and Acinetobacter baumannii were identified on 1st, 2nd, 4th, 9th drainage operation from the wound culture. According to culture result, the antibiotics changed ceftriaxone and aminoglycoside to vancomycin after that 9th drainage operation.

Despite three attempted esophageal repairs and VAC therapy, the perforation did not heal until 56 days after the esophageal perforation diagnosis. Fifty-nine days after the first drainage operation, on the 18th drainage operation, granulation tissue around the esophageal perforation began to grow, filling the dead space and finally sealing the perforation. The skin was closed with 3-0 nylon after insertion of a Barovac drainage tube (Sewoon Medical, Seoul, Korea). The esophagography performed on the 73th days after the esophageal perforation diagnosis, and showed the absence of the fistula and reflux. Six days later, the oral feeding started.

On the 90th days after the first drainage operation, edema within dead space of the neck decreased and CT revealed the absence of fluid filling the space. The gastrostomy tube was removed because complete oral feeding was possible before discharge. After complete healing of the esophageal perforation, the patient still complained of swallowing difficulty. So, rehabilitation for swallowing was performed. The swallowing problem improved, the patient was discharged on the 109th days after the first drainage operation.

One year after discharge, the iodine whole body scan revealed no uptake at the thyroid adhesion site of esophageal and trachea.

\section{Discussion}

Most esophageal perforations in the neck occur spontaneously or during airway intubation. Rarely, they occur during esophageal dilatation for strictures. They can occur during many operations, but perforation occurring after thyroidectomy is unusual. ${ }^{2,7)}$ Brinster, et al. ${ }^{8)}$ reported that $2 \%$ of 559 patient with esophageal perforation were due to operation injury in a review of literature. A Pubmed search was conducted using the term 'esophageal perforation' and 'thyroidectomy', first in the title and abstract, then 5 cases result were retrieved. ${ }^{1-5)}$

The symptoms and signs of esophageal perforation include neck pain, chest pain, dysphagia, dyspnea, stomach and abdominal discomfort, fever when aggravated to subcutaneous emphysema, leukocytosis and sepsis. ${ }^{9}$

The various symptoms make it difficult to diagnose esophageal perforation quickly, so treatment may be delayed. Therefore if patient complain of the aforementioned symptoms, 
imaging studies including chest and neck CT are necessary for diagnosis; if esophageal perforation is suspected, esophagography should be done immediately. ${ }^{8)}$ In this case, the patient complained of neck pain on the day of surgery, but the neck pain was regarded as a symptom that frequently occurs after surgery. After oral feeding the next evening, the drainage color darkened and neck swelling occurred; these indicated esophageal perforation. In such cases, if esophageal perforation is diagnosed correctly, immediate treatment rather than imaging study is required.

If the treatment is delayed 24 hours, necrosis will progress, which increases the mortality and morbidity rates to 5.5$29 \%$ associated with esophageal perforation. ${ }^{8)}$ Conservative treatment for esophageal perforation, which includes broadspectrum antibiotics, nutritional supply, has been considered for select patients with well-contained perforations, minimal contamination and no life threatening sepsis. ${ }^{2,5,7)}$ If these treatment unsuccessful, individualized operative treatments such as esophageal stent insertion, repair of the perforation site, transplantation, reconstruction and esophagectomy should be considered. ${ }^{7,10,11)}$ However, aggressive treatment for esophageal perforation such as esophagectomy, stent-grafting and transplantation reconstruction was markedly increased modality to $20 \%$, whereas primary repair was associated with a mortality rate of $9.5 \%{ }^{11)}$ Therefore, the patient's conditions, and aspect of perforation including cause, clinical symptoms, time of occurrence, location and size should be identified before determining whether to treat conservatively or to perform surgery. ${ }^{12)}$ If an infection occurs due to contamination following esophageal perforation, emergency operation is required because life may be threatened due to descending mediastinitis or mediastinal abscess. ${ }^{4,7)}$

In this case, although the patient received primary esophageal repair after conservative treatment, deep neck abscess and mediastinitis occurred after 2 days. It is thought that food material leaking from the perforation contaminated the neck wound and aggravated the infection. Drainage and saline irrigation were repeatedly performed to treat the abscess in the mediastinum. In this process, VAC therapy was applied instead of inserting a regular drainage tube.

In VAC therapy, the dead space is filled with a medical sponge after the wound is opened and continuous negative pressure is applied to the wound by connecting to negative pressure generating pump. The optimal pressure of VAC therapy has been recommended at $125 \mathrm{~mm} \mathrm{Hg}$ below ambient pressure based in the pioneering work of Morykwas, et al. ${ }^{13)}$
This method was introduced to treat complications of surgical or non-surgical wound. The therapy removes extracellular fluid, reduces edema in inflammation tissue, promotes proliferation of granulation tissue, and improves perfusion. ${ }^{13)}$ In the present case, while the patient was receiving VAC therapy, nasogastric tube was inserted. The insertion of nasogastric tube is helpful in identifying the location of esophagus during surgery, but also known to have advantage to be used for enteral feeding to prevent esophageal fistula. ${ }^{14)}$

Because the infection involved the mediastinum, the condition of the patient became worse. But after repeating VAC therapy 15 times, remission was observed in the neck wound. The white blood cell count changed irregularly during the follow-up period, but continuously decreased from the day of first drainage operation, which is consistent with the decreasing pattern of CRP level to $3 \mathrm{mg} / \mathrm{dL}$. CRP increased up to $11.8 \mathrm{mg} / \mathrm{dL}$ on the 9 th drainage operation day. At that time, a tracheal ulcer was detected but it healed spontaneously without further treatment. The tracheal ulcer might have increased CRP level. After that, CRP decreased gradually in accordance with the improvement of symptoms, which corresponds to the report that inflammation progress can be followed-up by monitoring CRP. ${ }^{15)}$

In our patient, esophageal perforation was primarily sutured three times early in treatment, but failed because the mucous membrane became thin due to severe inflammation. After multiple VAC therapy, the esophageal perforation healed gradually and was surrounded by healthy granulation. At the same time the abscess was reduced rapidly. The aggressive treatments mentioned above have low success rate and high morbidity. This suggest that VAC therapy might be an optional treatment for esophageal perforation with deep neck infection instead of aggressive surgical treatments like transplantation reconstruction or esophagectomy if primary repair fails in treatment of esophageal perforation accompanied by abscess or there is no improvement in spite of conservative therapy. ${ }^{10,14)}$

When esophageal perforation occurs after thyroidectomy, a quick diagnosis and adequate treatment are needed. It is most important to prevent the perforation. The surgeon must perform thyroidectomy more carefully if severe fibrosis or adhesion is found near esophagus. ${ }^{4)}$ In addition, if accompanied by deep neck infection and mediastinal infection, the cooperative effort of a thoracic surgeon may be helpful in the treatment of complicated areas including the esophagus, trachea and mediastinum. 


\section{REFERENCES}

1) Akbulut G, Gunay S, Aren A, Bilge O. A rare complication after thyroidectomy: esophageal perforation. Ulus Travma Derg 2002;8(4): 250-2.

2) Rabie ME. Hypopharyngeal fistula complicating difficult thyroidectomy for invasive papillary cancer. Ann R Coll Surg Engl 2014;96(7):e24-6.

3) Conzo G, Stanzione F, Della Pietra C, Palazzo A, Candilio G, Fiorelli A, et al. Tracheal necrosis, oesophageal fistula: unusual complications of thyroidectomy. Report of two case and literature review. Ann Ital Chir 2012;83(3):259-64.

4) Ozer MT, Demirbas S, Harlak A, Ersoz N, Eryilmaz M, Cetiner S. A rare complication after thyroidectomy: perforation of the oesophagus: a case report. Acta Chir Belg 2009;109(4):527-30.

5) Ward ND, Lee CY, Lee JT, Sloan DA. Esophageal fistula complicating thyroid lobectomy. J Surg Case Rep 2015;2015(1): rju136.

6) Brito TP, Hazboun IM, Fernandes FL, Bento LR, Zappelini CE, Chone CT, et al. Deep neck abscesses: study of 101 cases. Braz J Otorhinolaryngol 2016 May 5 [Epup]. http://dx.doi.org/10.1016/j. bjorl.2016.04.004.

7) Bufkin BL, Miller JI Jr, Mansour KA. Esophageal perforation: emphasis on management. Ann Thorac Surg 1996;61(5):1447-51; discussion 1451-2.

8) Brinster CJ, Singhal S, Lee L, Marshall MB, Kaiser LR, Kucharczuk JC. Evolving options in the management of esophageal perforation.
Ann Thorac Surg 2004;77(4):1475-83.

9) Altorjay A, Kiss J, Vörös A, Bohák A. Nonoperative management of esophageal perforations. Is it justified? Ann Surg 1997;225(4): 415-21.

10) Peng A, Li Y, Xiao Z, Wu W. Study of clinical treatment of esophageal foreign body-induced esophageal perforation with lethal complications. Eur Arch Otorhinolaryngol 2012;269(9):2027-36.

11) Biancari F, D’Andrea V, Paone R, Di Marco C, Savino G, Koivukangas $\mathrm{V}$, et al. Current treatment and outcome of esophageal perforations in adults: systematic review and meta-analysis of 75 studies. World J Surg 2013;37(5):1051-9.

12) Abbas G, Schuchert MJ, Pettiford BL, Pennathur A, Landreneau J, Landreneau J, et al. Contemporaneous management of esophageal perforation. Surgery 2009;146(4):749-55; discussion 755-6.

13) Morykwas MJ, Argenta LC, Shelton-Brown EI, McGuirt W. Vacuumassisted closure: a new method for wound control and treatment: animal studies and basic foundation. Ann Plast Surg 1997;38(6):55362.

14) Yoon BW, Yi KI, Kang JH, Kim SG, Cha W. Negative pressure wound therapy for cervical esophageal perforation with abscess. Auris Nasus Larynx 2015;42(3):254-7.

15) Cho K, Yoo Y. Clinical characteristics of medically intractable deep neck infection patients. Korean J Otorhinolaryngol-Head Neck Surg 2009;52(1):62-6. 